\title{
Activation of heat shock response improves biomarkers of NAFLD in patients with metabolic diseases
}

\author{
Tatsuya Kondo ${ }^{1, *}$, Nobukazu Miyakawa',*, Sayaka Kitano ${ }^{1}$, Takuro Watanabe $^{2}$, Rieko Goto ${ }^{2}$, Mary Ann Suico ${ }^{3}$, \\ Miki Sato ${ }^{2}$, Yuki Takaki ${ }^{2}$, Masaji Sakaguchi ${ }^{2}$, Motoyuki Igata' ${ }^{1}$, Junji Kawashima ${ }^{2}$, Hiroyuki Motoshima ${ }^{2}$, \\ Takeshi Matsumura², Hirofumi Kai ${ }^{3}$ and Eiichi Araki ${ }^{2}$ \\ 'Department of Diabetes, Metabolism and Endocrinology, Kumamoto University Hospital, Chuo-Ward, Kumamoto, Japan \\ ${ }^{2}$ Department of Metabolic Medicine, Faculty of Life Sciences, Kumamoto University, Chuo-Ward, Kumamoto, Japan \\ ${ }^{3}$ Department of Molecular Medicine, Faculty of Life Sciences, Kumamoto University, Chuo-Ward, Kumamoto, Japan \\ Correspondence should be addressed to T Kondo: t-kondo@gpo.kumamoto-u.ac.jp \\ *(T Kondo and N Miyakawa contributed equally to this work)
}

\begin{abstract}
Nonalcoholic fatty liver disease (NAFLD) is often accompanied by metabolic disorders such as metabolic syndrome and type 2 diabetes (T2DM). Heat shock response (HSR) is one of the most important homeostatic abilities but is deteriorated by chronic metabolic insults. Heat shock (HS) with an appropriate mild electrical stimulation (MES) activates HSR and improves metabolic abnormalities including insulin resistance, hyperglycemia and inflammation in metabolic disorders. To analyze the effects of HS + MES treatment on NAFLD biomarkers, three cohorts including healthy men (two times/week, $n=10$ ), patients with metabolic syndrome (four times/week, $n=40)$, and patients with T2DM ( $n=100$; four times/week $(n=40)$ and two, four, seven times/week $(n=20$ each) ) treated with HS + MES were retrospectively analyzed. The healthy subjects showed no significant alterations in NAFLD biomarkers after the treatment. In patients with metabolic syndrome, many of the NAFLD steatosis markers, including fatty liver index, NAFLD-liver fat score, liver/spleen ratio and hepatic steatosis index and NAFLD fibrosis marker, aspartate aminotransferase/ alanine aminotransferase (AST/ALT) ratio, were improved upon the treatment. In patients with T2DM, all investigated NAFLD steatosis markers were improved and NAFLD fibrosis markers such as the AST/ALT ratio, fibrosis-4 index and NAFLD-fibrosis score were improved upon the treatment. Thus, HS + MES, a physical intervention, may become a novel treatment strategy for NAFLD as well as metabolic disorders.
\end{abstract}

\author{
Key Words \\ - heat shock response (HSR) \\ - type 2 diabetes (T2DM) \\ - nonalcoholic fatty liver \\ disease (NAFLD) \\ - endoplasmic reticulum (ER) \\ stress
}

\section{Introduction}

The increasing worldwide prevalence of obesity and type 2 diabetes, which are closely associated with the development of NAFLD, has become a major healthcare problem (1). NAFLD encompasses a broad spectrum of disorders ranging from simple hepatic steatosis to its inflammatory variant, nonalcoholic steatohepatitis (NASH); progressive fibrosis; cirrhosis and eventually hepatocellular carcinoma in the absence of significant alcohol consumption. NAFLD is considered an important phenotype in metabolic diseases, such as metabolic syndrome and type 2 diabetes. These metabolic disturbances are closely associated with insulin resistance. Hepatic insulin resistance also causes dyslipidemia, oxidative stress, endoplasmic reticulum (ER) stress, and a 
pro-inflammatory state, all of which further contribute to the development and progression of NAFLD (2). A recent study indicated that patients with fatty liver alone or the accumulation of visceral fat with fatty liver demonstrated more significant insulin resistance in adipose tissue, muscle, and liver than patients with the accumulation of visceral fat alone (3). These data suggest that the fatty liver may be more closely associated with insulin resistance than the accumulation of visceral fat. In other words, targeting NAFLD could be beneficial for regulating insulin resistance and vice versa.

Perturbation of ER homeostasis, referred to as 'ER stress', is associated with numerous pathological conditions such as inflammation, cardiovascular disease, and metabolic disorders including NAFLD (4). ER stress in the liver and NAFLD is closely associated with the development of hepatic insulin resistance (5).

Our interests are focused on the role of the HSR in metabolic diseases and insulin resistance. We have investigated the beneficial effects of the activation of the HSR by both chemical and physical medical interventions. Heat shock protein (HSP) 72 is a major effector of the HSR pathway and acts to protect cells or tissues from external/environmental and internal stimuli such as heat stress, UV light, heavy metals, infection, chronic hyperglycemia, and systemic inflammation. Our previous reports suggest that HSP72 induction by geranylgeranylacetone (GGA) or heat shock (HS) + mild electrical stimulation (MES) attenuates metabolic abnormalities such as glucose intolerance, insulin resistance, chronic inflammation, enhanced hepatic gluconeogenesis, and steatosis in mouse models of diabetes as well as in patients with metabolic syndrome and type 2 diabetes $(6,7,8)$. The introduction of HSP72 specifically in the liver of whole-body HSP72 knockout mice by lentivirus resulted in the amelioration of whole-body glucose homeostasis and inflammation as well as hepatic gluconeogenesis and steatosis (9). Therefore, the hepatic role of HSP72 should be more precisely investigated. Re-evaluation of the effects of NAFLD biomarkers on HS + MES treatment could provide additional insights into the relationship between HSP72 and NAFLD. Thus, the effects of HS+MES on NAFLD biomarkers have been retrospectively analyzed in three different cohorts. The present study aimed to investigate the effects of HS+MES on NAFLD biomarkers in patients with metabolic syndrome and patients with type 2 diabetes.

\section{Materials and methods}

In this retrospective observational study, three different cohort studies previously conducted were reinvestigated to evaluate the effects of HS+MES (10) therapy with respect to whether this intervention improves NAFLD biomarkers in healthy men, patients with metabolic syndrome, or patients with type 2 diabetes. All those methods were carried out in accordance with relevant guidelines and regulations (11).

\section{Study participants}

\section{Cohort 1}

Cohort 1 comprised 10 healthy subjects. This was a singlearm, before-after trial of an intervention (HS + MES twice a week) (10). This study was approved by the institutional review board of Kumamoto University (No. 154). This clinical trial was registered with an approved ICMJE clinical trial registry, UMIN (ID: UMIN000001336).

\section{Cohort 2}

Cohort 2 comprised 40 patients with metabolic syndrome. The definition of metabolic syndrome in the Examination Committee for Criteria of Metabolic Syndrome was employed for the diagnosis of metabolic syndrome (12). Briefly, a metabolicsyndromewas defined as a condition that involves any two of the following conditions, in addition to visceral fat accumulation (waist circumference $\geq 85 \mathrm{~cm}$ in men): fasting hyperglycemia $\geq 110 \mathrm{mg} / \mathrm{dL}$, dyslipidemia such as hypertriglyceridemia ( $\geq 150 \mathrm{mg} / \mathrm{dL}$ ), hypo HDLcholesterolemia $(<40 \mathrm{mg} / \mathrm{dL})$, and high blood pressure $(\geq 130 / 85 \mathrm{mmHg}$ ). This was an open-label crossover trial (HS + MES four times a week) (8). This study was approved by the institutional review board of Kumamoto University (Advanced Ethics No. 736). The clinical trial was registered with an approved ICMJE clinical trial registry, UMIN (ID: UMIN 000001149).

\section{Cohort 3}

Cohort 3 comprised 100 patients with type 2 diabetes. Type 2 diabetes was diagnosed on the basis of the criteria of the American Diabetes Association (13). Briefly, type 2 diabetes was defined as $\mathrm{HbA1c} \geq 6.5 \%$, fasting glucose $\geq 126 \mathrm{mg} / \mathrm{dL}$, post-prandial glucose $\geq 200 \mathrm{mg} / \mathrm{dL}$ or the usage of anti-diabetic agents. This cohort contained an open-label crossover trial (HS + MES four times a week) (8) and a triple-arm before-after trial of an intervention

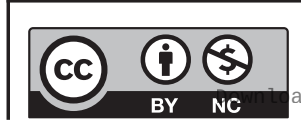

This work is licensed under a Creative Commons Attribution-NonCommercial 4.0 International License. ded from Bioscientifica.com at 04/26/2023 12:09:44PM 
(HS + MES two, four, or seven times a week) (7). These studies were approved by the institutional review board of Kumamoto University (Advanced Ethics No. 514). The clinical trial was registered with an approved ICMJE clinical trial registry, UMIN (ID: UMIN 000003210, and UMIN 000016309, respectively). In total, 150 Japanese subjects were treated with HS+MES for 8 to 12 weeks. The inclusion and exclusion criteria are described elsewhere (7, $8,10)$. Informed consent was obtained from all subjects.

\section{HS + MES treatment}

The device (BioMetronome) used to produce HS + MES was provided by Tsuchiya Rubber Co. Ltd. (Kumamoto, Japan). MES was delivered from abdominal (positive electrode) to lower back surfaces (negative electrode) on subjects' body using a pair of electro-conductive and thermo-generative rubber electrodes of size $15 \mathrm{~cm}$ in length and $25 \mathrm{~cm}$ in width, which were padded with a soft cotton cloth. The electrodes were connected to an HS+MES generator that delivered $1.4 \pm 0.1 \mathrm{~V} / \mathrm{cm}$ (55 pulses/s) of direct current with an individual duration of 0.1 millisecond. Temperature at the surface of the electrode was adjusted to $42^{\circ} \mathrm{C}$. HS + MES treatment was performed at each subject's home, and complete adherence was confirmed by logs that the subjects were instructed to fill out at the time of treatment.

\section{NAFLD biomarkers}

\section{NAFLD steatosis biomarkers}

Fatty liver index (FLI) The FLI was introduced in 2006 (14) and is considered a simple and accurate predictor of hepatic steatosis. The FLI has shown good performance in detecting hepatic steatosis in several population studies (15). The FLI is a prevalent biomarker panel consisting of the BMI, waist circumference (Wc), TGs, and gammaglutamyl transferase ( $\gamma$-GTP). It is used to identify NAFLD and has a total score of 0 to 100, the cut-off value was designated as 30 (14).

$$
\begin{aligned}
& \mathrm{FLI}=\left(\mathrm{e} 0.953 \times \log _{\mathrm{e}}(\mathrm{TG})+0.139 \times \mathrm{BMI}+0.718 \times\right. \\
& \left.\log _{\mathrm{e}}(\gamma-\mathrm{GTP})+0.053 \times \mathrm{Wc}-15.745\right) /(1+\mathrm{e} 0.953 \times \\
& \log _{\mathrm{e}}(\mathrm{TG})+0.139 \times \mathrm{BMI}+0.718 \times \log _{\mathrm{e}}(\gamma-\mathrm{GTP})+0.053 \times \\
& \mathrm{Wc}-15.745) \times 100
\end{aligned}
$$

NAFLD-liver fat score (NAFLD-LFS) The NAFLD-LFS has been proposed (16) and validated against magnetic resonance spectroscopy, showing an overall good accuracy in diagnosing NAFLD (15). It integrates the levels of fasting insulin and transaminases as well as the presence of the metabolic syndrome. The NAFLD-LFS provides similarly good NAFLD prediction compared with the FLI. The cut-off value was designated as -0.640 (16).

NAFLD-LFS $=-2.89+1.18 \times$ metabolic syndrome (yes: 1 , no: 0$)+0.45 \times$ type 2 diabetes (yes: 2 , no: 0$)+$ $0.15 \times$ insulin $(\mu \mathrm{U} / \mathrm{L})+0.04 \times \operatorname{AST}(\mathrm{U} / \mathrm{L})-0.94 \times$ AST/ALT

Liver/spleen (L/S) attenuation ratio in computed tomography (CT) Unenhanced CT is more specific than ultrasound for the detection of NAFLD. Hepatic steatosis manifests as reduced attenuation in the liver parenchyma, which correlates with the degree of intrahepatic fat accumulation. The L/S Hounsfield unit ratio (cut-off value as 1.0) calculated using CT scans in patients with type 2 diabetes $(17,18)$ is reportedly useful for evaluation of the hepatic lipid content.

Hepatic steatosis index (HSI) The HSI, derived from the data of a Korean cross-sectional case-control study involving more than 10,000 patients (19), is a simple and promising score for predicting NAFLD (15). The HSI may offer an economical and noninvasive means of predicting the presence of NAFLD with reasonable accuracy (cutoff value as 36). The HSI is a biomarker panel consisting of the BMI, presence of diabetes, and ALT/AST ratio. $\mathrm{HSI}=8$ $\times$ ALT/AST + BMI (+2: if type 2 diabetes, +2 : if female).

Visceral adiposity index (VAI) The VAI is a surrogate biomarker of visceral adiposity and hepatic steatosis (20). A dose-response relationship exists between the VAI (cutoff value as 1.92) and the risk of NAFLD in that a higher VAI is correlated with an increased incidence of NAFLD.

$$
\begin{aligned}
& \mathrm{VAI}=(\mathrm{Wc} /(39.68+(1.88 \times \mathrm{BMI})) \times(\mathrm{TG} / 1.03) \times \\
& (1.31 / \mathrm{HDL}) \text { for males, }(\mathrm{Wc} / 36.58+1.89 \times \mathrm{BMI}) \times \\
& (\mathrm{TG} / 0.81) \times(1.52 / \mathrm{HDL}) \text { for females, where } \mathrm{HDL} \text { is the } \\
& \text { high-density lipoprotein level. }
\end{aligned}
$$

TG $\times$ fasting glucose (TyG) index The TyG index (cutoff value as 4.49), an indirect score of insulin resistance, has been demonstrated to be independently associated with histologically defined steatosis (21).

$$
\text { TyG index }=\log ((\mathrm{TG}) \times \text { glucose } / 2)
$$

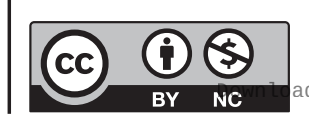

This work is licensed under a Creative Commons Attribution-NonCommercial 4.0 International License. ded from Bioscientifica.com at 04/26/2023 12:09:44PM via free access 


\section{NAFLD fibrosis biomarkers}

Aspartate aminotransferase (AST)/alanine aminotransferase (ALT) ratio The AST/ALT ratio was originally developed for the characterization of acute viral hepatitis by De Ritis (22). This ratio recently became considered as a fibrosis marker rather than a steatosis marker (23). Metabolic disturbances as insulin resistance, dyslipidemia, and hyperglycemia are closely related to elevated ALT concentrations; an AST/ALT ratio cut-off point of $<1.0$ has been defined for hepatic fibrosis assessment in patients with obesity (24).

Fibrosis-4 (FIB4) index The FIB4 index (cut-off value as 1.45 ) is considered useful, reliable, and inexpensive for evaluating hepatic fibrosis (25). It is superior to other noninvasive markers of hepatic fibrosis in Japanese patients with NAFLD, with a high negative predictive value for excluding advanced fibrosis (26).

FIB4 $=($ age $($ years $) \times$ AST $(\mathrm{U} / \mathrm{L})) /\left(\right.$ platelet count $\left(10^{9} / \mathrm{L}\right) \times$ $\left.\operatorname{ALT}(\mathrm{U} / \mathrm{L})^{1 / 2}\right)(26)$

NAFLD-fibrosis score (NFS) The NFS (cut-off value as -1.455 ) has been externally validated in ethnically different NAFLD populations with consistent results (27). It is used to distinguish patients with NAFLD who do and do not have advanced liver fibrosis.

$\mathrm{NFS}=-1.675+0.037 \times$ age $($ years $)+0.094 \times \mathrm{BMI}+1.13$

$\times$ impaired fasting glycemia/diabetes (yes $=1$, no $=0)+0.99 \times$ AST/ALT $-0.013 \times$ platelet count $\left(\times 10^{9} / \mathrm{L}\right)-0.66 \times$ albumin $(\mathrm{g} / \mathrm{dL})$

AST-to-platelet ratio index (APRI) The APRI (cut-off value as 1.0) was developed to predict fibrosis staging in noninvasive manner (28).

$\mathrm{APRI}=(\mathrm{AST} \times(\mathrm{AST}$ upper limit of normal $) /$ platelet count $\left(10^{9} / \mathrm{L}\right) \times 100$

\section{Statistical analysis}

Statistical analysis was performed with SPSS 16.0 software (IBM Corp.). Values are expressed as mean \pm s.D. or media with 25 th percentile to 75 th percentile. All the outliners have been included in the analyses. Wilcoxon signed-rank test was employed to compare the median values of each
NAFLD biomarker which were not distributed normally. The differences among the multiple groups were primarily analyzed using an analysis of covariance (ANCOVA). Age and baseline values were used as covariates in ANCOVA analysis. Then, post-hoc procedures (Bonferroni pairwise tests) were used to examine particular differences between the groups. Univariable linear regression analysis was carried out to examine the association between delta NAFLD biomarkers and cumulative exposure time of HS + MES treatment. Categorical variables were assessed using proposed respective cut-off values of NAFLD biomarkers by performing chi-square analysis with Fisher's exact test when the number of data points was small. Two-sided $P$-values of $<0.05$ were considered to indicate statistical significance.

\section{Results}

\section{Study participants}

The general baseline characteristics of the study participants are summarized in Table 1. In this study, we have 150 participants with 132 male (88\%) and 18 female $(12 \%)$. In general, patients with type 2 diabetes were older, had a higher incidence of obesity with visceral fat accumulation, had higher glucose levels, had more severe NAFLD steatosis/fibrosis markers and had a more inflammatory-prone phenotype at baseline (Table 1). All participants were treated with HS + MES from two to seven times a week, 30 to 60 min per session, for 8 to 12 weeks depending on the particular study design (Supplementary Fig. 1, see section on supplementary materials given at the end of this article). No serious adverse events or hypoglycemia over the periods of each intervention were found. The status of NAFLD was estimated and evaluated by NAFLD steatosis markers (fatty liver index (FLI), NAFLDliver fat score (LFS), liver/spleen (L/S) ratio, and hepatic steatosis index (HSI), visceral adiposity index (VAI) and triglyceride $\times$ fasting glucose index $($ TyG)), and NAFLD fibrosis markers (aspartate aminotransferase/alanine aminotransferase (AST/ALT) ratio, fibrosis-4 index (FIB4), NAFLD-fibrosis score (NFS) and AST-to-platelet ratio index (APRI)). All outliners have been included in the analyses.

\section{Healthy subjects}

The healthy subjects showed no significant alterations in the NAFLD steatosis or fibrosis markers after HS + MES treatment (Figs 1 and 2). Categorical analysis using
This work is licensed under a Creative Commons Attribution-NonCommercial 4.0 International License. ded from Bioscientifica.com at 04/26/2023 12:09:44PM via free access 
Table 1 Baseline characteristics of the study participants.

\begin{tabular}{|c|c|c|c|c|}
\hline & Healthy subjects & Metabolic syndrome & Type 2 diabetes & P-value \\
\hline Number of participants & 10 & 40 & 100 & \\
\hline Age (years) & $34.0 \pm 4.7$ & $52.7 \pm 6.8^{\ddagger}$ & $62.7 \pm 11.6^{1 \|^{* *}}$ & 0.002 \\
\hline Male (\%) & 100 & 100 & 82 & \\
\hline Diabetes history (years) & N.A. & N.A. & $8.79 \pm 5.13$ & \\
\hline \multicolumn{5}{|l|}{ Medications } \\
\hline Sulfnylurea & N.A. & N.A. & $54 \%$ & \\
\hline Biguanide & N.A. & N.A. & $55 \%$ & \\
\hline$\alpha$-glucosidase inhibitor & N.A. & N.A. & $17 \%$ & \\
\hline Glinide & N.A. & N.A. & $3 \%$ & \\
\hline Pioglitazone & N.A. & N.A. & $22 \%$ & \\
\hline Dipeptidyl peptidase-4 inhibitor & N.A. & N.A. & $42 \%$ & \\
\hline Sodium-glucose cotransporter 2 inhibitor & N.A. & N.A. & $0 \%$ & \\
\hline \multicolumn{5}{|l|}{ Adiposity } \\
\hline Visceral fat area & $3400.5 \pm 1401.3 \mathrm{~cm}^{3 *}$ & $148.4 \pm 40.8 \mathrm{~cm}^{2}$ & $174.1 \pm 61.7 \mathrm{~cm}^{2 * *}$ & 0.004 \\
\hline s.c. fat area & $4464.5 \pm 2353.3 \mathrm{~cm}^{3 *}$ & $191.7 \pm 60.7 \mathrm{~cm}^{2}$ & $188.4 \pm 87.3 \mathrm{~cm}^{29}$ & 0.016 \\
\hline Total fat area & $7865.0 \pm 3689.7 \mathrm{~cm}^{3^{*}}$ & $340.1 \pm 84.4 \mathrm{~cm}^{2}$ & $362.5 \pm 125.9 \mathrm{~cm}^{2}$ & \\
\hline $\mathrm{BMI}\left(\mathrm{kg} / \mathrm{m}^{2}\right)$ & $23.7 \pm 2.9$ & $26.8 \pm 2.9^{\ddagger}$ & $28.6 \pm 4.6 \|^{11^{* *}}$ & 0.011 \\
\hline Wc $(\mathrm{cm})$ & $82.7 \pm 10.2$ & $94.1 \pm 6.4^{\ddagger}$ & $99.1 \pm 11.3^{\prime \prime}$ & 0.028 \\
\hline \multicolumn{5}{|l|}{ Blood pressure } \\
\hline Systolic blood pressure (mmHg) & $122.7 \pm 9.2$ & $135.5 \pm 16.0^{\dagger}$ & $137.9 \pm 17.6^{\S}$ & 0.004 \\
\hline Diastolic blood pressure (mmHg) & $72.5 \pm 8.7$ & $85.8 \pm 11.1^{\ddagger}$ & $76.9 \pm 10.6$ & 0.001 \\
\hline Heart rate $(\mathrm{bpm})$ & $76.8 \pm 13.4$ & $68.9 \pm 8.8$ & $74.2 \pm 12.7$ & \\
\hline \multicolumn{5}{|l|}{ Glucose control and insulin resistance } \\
\hline Fasting plasma glucose (mg/dL) & $92.1 \pm 6.0$ & $112.3 \pm 11.4^{\ddagger}$ & $154.7 \pm 42.9 \|^{\prime, * *}$ & 0.0001 \\
\hline Fasting immuno-reactive insulin $(\mu \mathrm{lU} / \mathrm{mL})$ & $7.5 \pm 3.3$ & $11.4 \pm 6.2$ & $11.6 \pm 9.9$ & \\
\hline HOMA-IR & $1.72 \pm 0.78$ & $3.16 \pm 1.67^{\ddagger}$ & $4.63 \pm 4.52^{11, * *}$ & 0.0001 \\
\hline $\mathrm{HbA} 1 \mathrm{c}(\%)$ & $4.97 \pm 0.21$ & $5.24 \pm 0.57^{\dagger}$ & $7.52 \pm 0.83^{1 \|^{* *}}$ & 0.003 \\
\hline Glycated albumin (\%) & N.A. & N.A. & $19.1 \pm 3.2$ & \\
\hline Adiponectin $(\mu \mathrm{g} / \mathrm{mL})$ & $6.50 \pm 1.84$ & $2.77 \pm 1.53^{\ddagger}$ & $6.4 \pm 4.0^{* *}$ & 0.018 \\
\hline \multicolumn{5}{|l|}{ NAFLD markers and lipids } \\
\hline AST (IU/L) & $20.8 \pm 6.6$ & $22.7 \pm 8.6$ & $30.5 \pm 16.3$ & \\
\hline ALT (IU/L) & $23.7 \pm 11.3$ & $30.5 \pm 14.0$ & $36.2 \pm 21.5$ & \\
\hline \multicolumn{5}{|l|}{ NAFLD steatosis markers } \\
\hline Fatty liver index (FLI) & N.A. & $63.0(48.0-77.3)$ & $63.6(45.7-87.2)$ & \\
\hline NAFLD-liver fat score (LFS) & N.A. & $-0.17(-0.71$ to 0.34$)$ & $1.06(0.40-2.04)^{* *}$ & 0.006 \\
\hline Liver/spleen ratio & N.A. & $0.99(0.89-1.11)$ & $0.98(0.89-1.07)$ & \\
\hline Hepatic steatosis index (HSI) & $31.9(28.9-35.8)$ & $37.4(34.1-39.6)^{\ddagger}$ & $39.3(36.4-44.8)^{1, \ldots *}$ & 0.012 \\
\hline Visceral adiposity index (VAI) & $0.68(0.41-0.95)$ & $1.69(1.30-2.18)^{\ddagger}$ & $3.28(2.26-5.53)^{1, \ldots *}$ & 0.009 \\
\hline Triglyceride $\times$ glucose $($ TyG $)$ & $3.43(3.35-3.70)$ & $3.91(3.82-4.01)^{\dagger}$ & $4.05(3.84-4.19)^{||, 9 \mid}$ & 0.028 \\
\hline \multicolumn{5}{|l|}{ NAFLD fibrosis markers } \\
\hline AST/ALT & $0.98(0.85-1.06)$ & $0.80(0.65-0.92)$ & $0.94(0.71-1.06)^{\star *}$ & 0.023 \\
\hline FIB4 index & $0.71(0.67-0.82)$ & $1.00(0.82-1.25)^{\ddagger}$ & $1.43(1.04-2.11)^{1, * \star}$ & 0.007 \\
\hline NAFLD-fibrosis score (FS) & N.A. & $-1.20(-1.66$ to -0.69$)$ & $-0.20(-1.11 \text { to }-0.71)^{* *}$ & 0.012 \\
\hline AST to platelet ratio Index (APRI) & N.A. & $0.36(0.28-0.39)$ & $0.41(0.30-0.58)^{9}$ & 0.011 \\
\hline LDL-C (mg/dL) & $128.2 \pm 27.7$ & $131.6 \pm 28.5$ & $113.6 \pm 29.3^{9}$ & 0.033 \\
\hline $\mathrm{HDL}-\mathrm{C}(\mathrm{mg} / \mathrm{dL})$ & $59.4 \pm 9.0$ & $50.4 \pm 8.5^{\ddagger}$ & $51.9 \pm 14.4$ & 0.048 \\
\hline $\mathrm{TG}(\mathrm{mg} / \mathrm{dL})$ & $78.7 \pm 40.4$ & $156.1 \pm 10.6^{\ddagger}$ & $174.3 \pm 124.011$ & 0.002 \\
\hline \multicolumn{5}{|l|}{ Systemic inflammation } \\
\hline TNF- $a(p g / m L)$ & $0.91 \pm 0.05$ & $1.41 \pm 0.58^{\ddagger}$ & $1.79 \pm 1.4111$ & 0.004 \\
\hline IL-6 (pg/mL) & $0.81 \pm 0.15$ & $1.45 \pm 0.86^{\dagger}$ & $3.08 \pm 2.45^{\S, * *}$ & 0.0012 \\
\hline hs-CRP (ng/mL) & $521.9 \pm 73.9$ & $767.9 \pm 971.2$ & $2750.6 \pm 7656.1$ & \\
\hline WBC $(/ \mu \mathrm{L})$ & $5220 \pm 542.8$ & $6015 \pm 1513$ & $6495.7 \pm 1675.4$ & \\
\hline
\end{tabular}

Values are numbers, $n$ (\%) or mean \pm S.D. or median with 25th percentile to 75 th percentile. For multiple group comparisons, $P$-values derived from ANCOVA analysis were indicated in most right. Post-hoc procedures (Bonferroni pairwise tests) were used to examine particular differences between the groups. *The volume was calculated; ${ }^{\dagger} P<0.05$ : H vs Mets; ${ }^{\ddagger} P<0.01$ : H vs Mets; ${ }^{5} P<0.05$ : H vs T2D; $\| P<0.01: \mathrm{H}$ vs T2D; ${ }^{\uparrow} P<0.05$ : Mets vs T2D; ${ }^{* *} P<0.01:$ Mets vs T2D. ALT, alanine aminotransferase; AST, aspartate aminotransferase; $\mathrm{H}$, healthy subjects; $\mathrm{HDL}-\mathrm{C}$, high-density lipoprotein cholesterol; TG, triglyceride; HOMA-IR, homeostasis model assessment as an index of insulin resistance; hs-CRP, high sensitivity C-reactive protein; IL-6, interleukin-6; LDL-C, low-density lipoprotein cholesterol; Mets, metabolic syndrome; N.A, not applicable;T2D, type 2 diabetes;TNF- $\alpha$, tumor necrosis factor- $\alpha$; WBC: white blood cell count; WC, waist circumference.

https://ec.bioscientifica.com https://doi.org/10.1530/EC-21-0084 (c) 2021 The authors Published by Bioscientifica Ltd

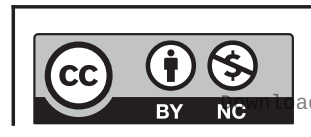

This work is licensed under a Creative Commons Attribution-NonCommercial 4.0 International License. ded from Bioscientifica.com at $04 / 26 / 2023$ 12:09:44PM 


\section{Healthy male}

HSI
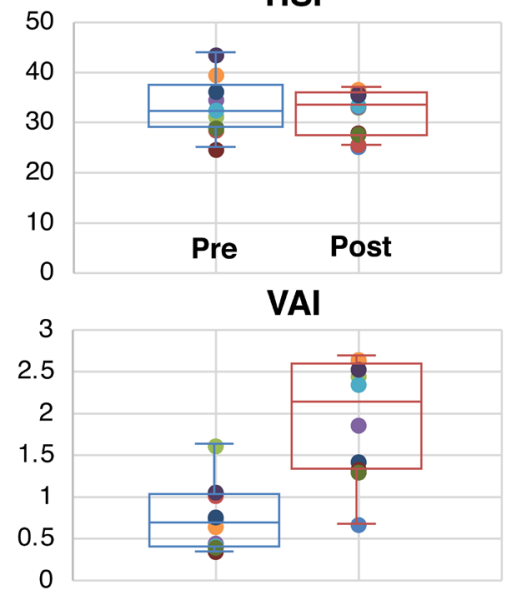

TyG

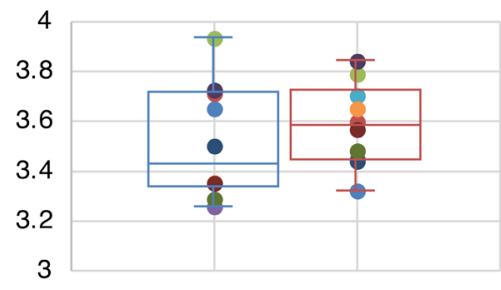

Metabolic syndrome

FLI

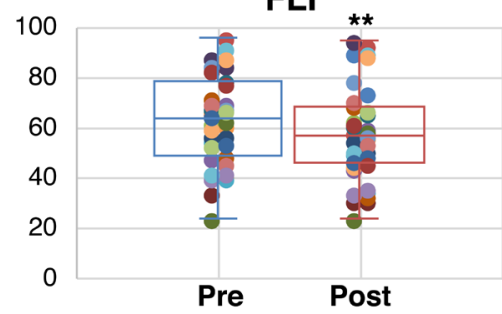

NAFLD-LFS

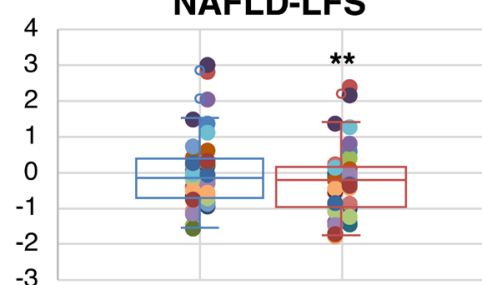

L/S ratio

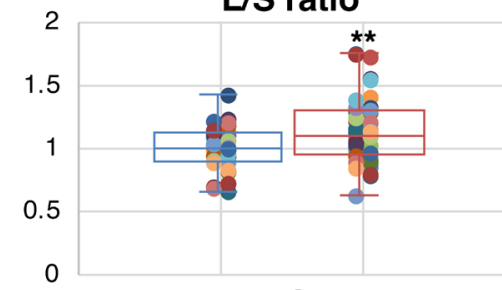

HSI
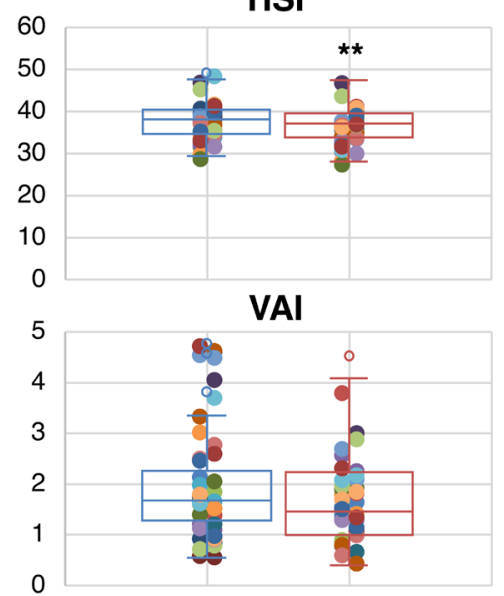

TyG

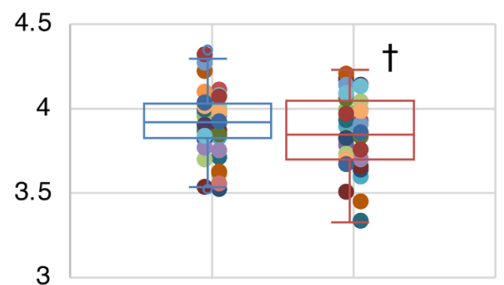

Type 2 diabetes

FLI

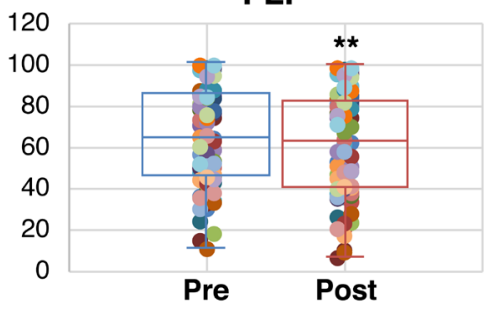

NAFLD-LFS

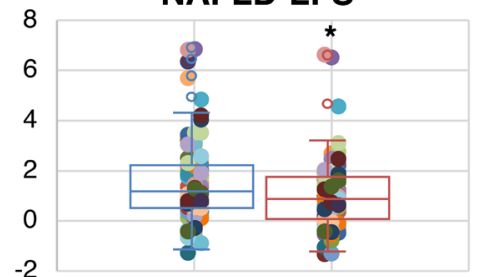

L/S ratio

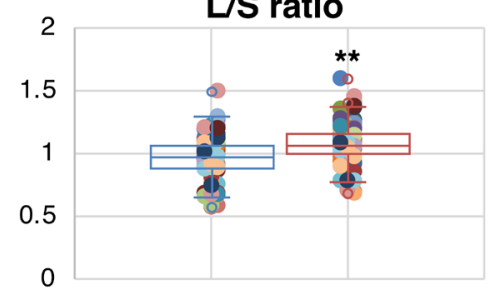

HSI

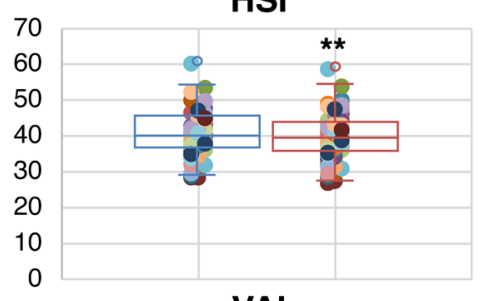

VAI

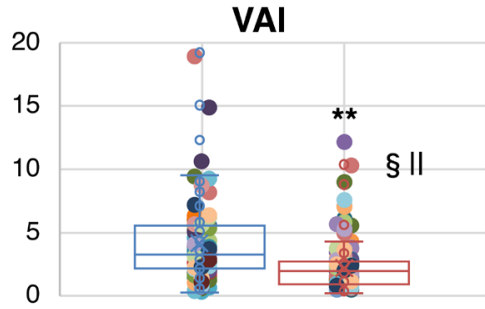

TyG

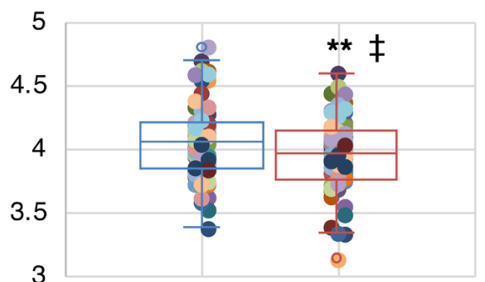

Figure 1

The changes in NAFLD steatosis biomarkers on HS + MES treatment. The absolute values (median with quartiles) of the NAFLD steatosis biomarkers such as fatty liver index (FLI), NAFLD-liver fat score (LFS), liver/spleen (L/S) ratio, hepatic steatosis index (HSI), visceral adiposity index (VAI) and triglyceride $\times$ glucose (TyG) were indicated at pre and post HS + MES treatment. ${ }^{*} P<0.05 .{ }^{* *} P<0.01$ compared to baseline. The multiple comparisons of delta changes in NAFLD biomarkers among the groups were performed. $P$-values derived from ANCOVA were 0.055 in delta HSI, 0.003 in delta VAI and 0.015 in delta TyG. $\dagger P<0.05$ : $\mathrm{H}$ vs Mets in delta TyG. $¥ P<0.01$ : Mets vs T2D in delta TyG. $\S P<0.01$ : H vs T2D in delta VAl. ||$P<0.01$ : Mets vs T2D in delta VAl.

https://ec.bioscientifica.com

https://doi.org/10.1530/EC-21-0084 (c) 2021 The authors Published by Bioscientifica Ltd

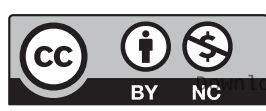

This work is licensed under a Creative Commons Attribution-NonCommercial 4.0 International License. ded from Bioscientifica.com at 04/26/2023 12:09:44PM 
Healthy male

AST/ALT

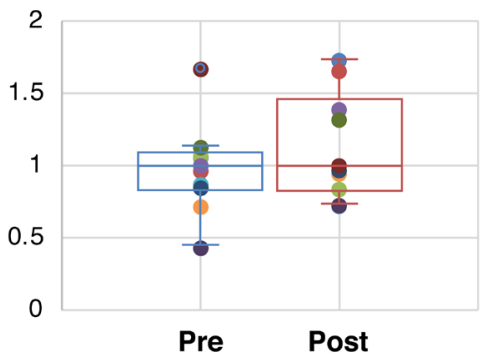

FIB4

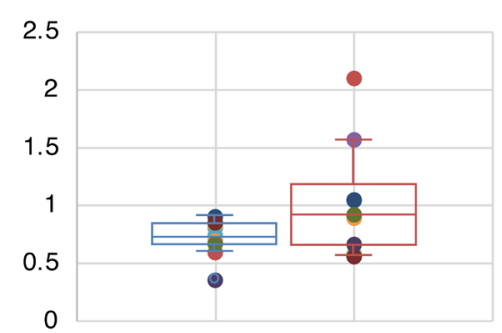

Metabolic syndrome

AST/ALT

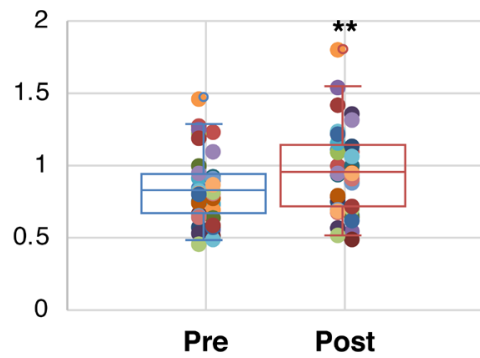

FIB4

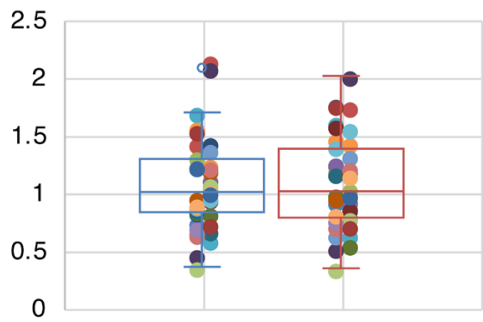

NAFLD-FS

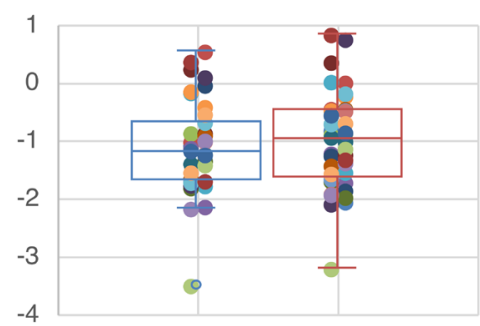

APRI

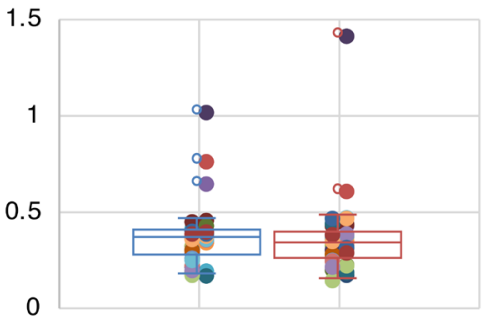

Type 2 diabetes

AST/ALT

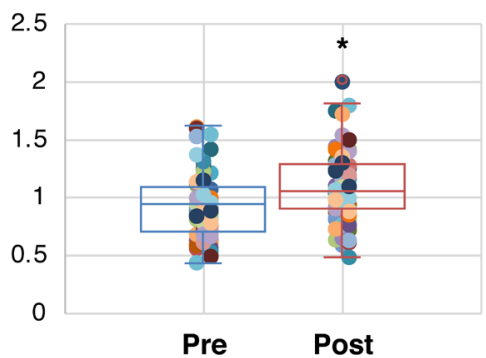

FIB4

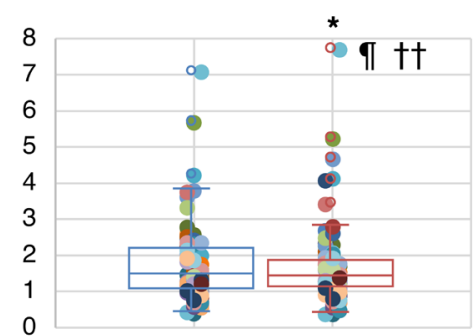

NAFLD-FS

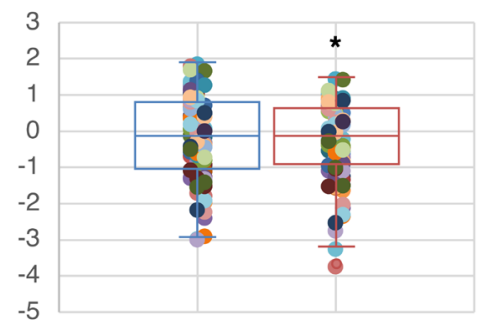

APRI

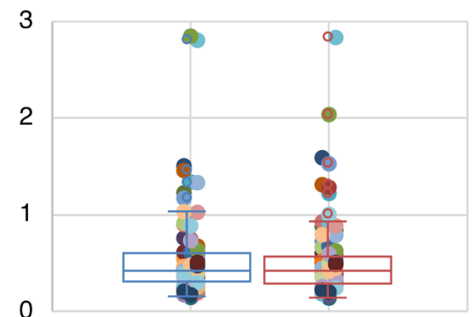

Figure 2

The changes in NAFLD fibrosis biomarkers on HS + MES treatment. The absolute values (median with quartiles) of the NAFLD fibrosis biomarkers such as AST/ALT ratio, FIB4 index, NAFLD-fibrosis score (NFS) and AST to platelet ratio index (APRI) were indicated pre and post MES + HS treatment. ${ }^{*} P<0.05$ compared to baseline. The multiple comparisons of delta changes in NAFLD biomarkers among the groups were performed. $P$-values derived from ANCOVA was 0.08 in delta AST/ALT, 0.002 in delta FIB4. ${ }^{~} P<0.01: \mathrm{H}$ vs T2D in delta FIB4. ${ }^{\dagger \dagger} P<0.05:$ Mets vs T2D in delta FIB4. 
previously designated cut-off values was also performed, and no significant changes were detected by HS + MES in healthy subjects.

\section{Metabolic syndrome}

In the patients with metabolic syndrome, many of the NAFLD steatosis markers were improved upon HS + MES treatment, including the FLI $(P=0.0016)$, NAFLD-LFS $(\mathrm{P}=0.0008), \mathrm{L} / \mathrm{S}$ ratio $(P=0.003)$, and HSI $(P=0.0004)$; however, the VAI and TyG were not (Fig. 1). In contrast, there were no significant alterations in NAFLD fibrosis markers except for AST/ALT ratio $(P=0.0003)$ after HS + MES treatment in patients with metabolic syndrome (Fig. 2). Categorical analysis using previously proposed cut-off values was also performed. L/S ratio (the ratio of the cut-off value more than 1.0 was increased from 50.0 to $70 \% . P=0.022$ ) and AST/ALT ratio (the ratio of the cut-off value more than 1.0 was increased from 20.0 to $40 \%$. $P=0.036)$ showed significant improvements upon HS + MES treatment.

\section{Type 2 diabetes}

In patients with type 2 diabetes, all investigated NAFLD steatosis markers were improved upon HS+MES treatment, including the FLI $(P=0.0001)$, NAFLD-LFS $(P=0.018), \mathrm{L} / \mathrm{S}$ ratio $(P=0.00003)$, HSI $(P=0.00006)$, VAI $(P=0.006)$, and TyG $(P=0.00003)$ (Fig. 1$)$. NAFLD fibrosis markers were also improved, including the AST/ALT ratio $(P=0.013)$, FIB4 index $(P=0.024)$ and NFS $(P=0.024)$, but the APRI was not (Fig. 2). Categorical analysis using previously designated cut-off values was also performed. FLI (the ratio of cut-off value less than 30 was increased from 4.0 to $12.0 \%$. $P=0.048$ ), $\mathrm{L} / \mathrm{S}$ ratio (the percentage of cut-off value more than 1.0 was increased from 46.0 to $78.0 \%$. $P=0.0001$ ), VAI (the percentage of cut-off value less than 1.92 was increased from 16.0 to $46.0 \%$. $P=0.001$ ), TyG (the ratio of cut-off value less than 4.49 was increased from 85.0 to $92.0 \% . P=0.036$ ) and AST/ALT ratio (the percentage of cut-off value more than 1.0 was increased from 44.0 to $69.0 \% . P=0.0001$ ) showed significant improvements upon HS+MES treatment.

\section{Cumulative intervention effects of MES + HS}

Because our study combined the results from different frequencies and duration of HS+MES treatment, cumulative intervention effects were investigated using cumulative exposure time (CET: time (minutes) $\times$ frequency/week $\times$ weeks). Univariable linear regression analysis was performed to evaluate whether the effects in NAFLD biomarkers of HS +MES were cumulative exposure time dependent. In Fig. 3, delta HSI $(P=0.039)$, delta TyG $(P=0.038)$, delta FIB4 $(P=0.037)$, delta NFS $(P=0.036)$ and delta APRI $(P=0.043)$ were linearly correlated with the cumulative exposure time.

\section{Differential effects MES + HS depending on the metabolic background}

The multiple comparisons of delta changes in NAFLD biomarkers among the groups may detect if the effectiveness of HS + MES may vary in different metabolic backgrounds. We found that the reduction in TyG $(-0.05$ vs +0.07 , adjusted $P=0.02(\dagger)$. Fig. 1$)$ was larger in metabolic syndrome than that in healthy subjects. The reduction in VAI $(-1.26$ vs +1.41 in healthy subjects or -0.22 metabolic syndrome. Adjusted $P=0.005(\S, \|)$, respectively. Fig. 1.) and FIB4 ( -0.10 vs +0.32 in healthy subjects (adjusted $P=0.008$ (II)) or +0.06 (adjusted $P=0.041(\dagger \dagger)$ ) in metabolic syndrome. Fig. 2.) were larger in type 2 diabetes than those in healthy subjects or in metabolic syndrome. The reduction in TyG ( -0.10 vs -0.05 , adjusted $P=0.002$ ( $\ddagger$ Fig. 1.) was larger in type 2 diabetes than that in metabolic syndrome. These data implicate that the trend of larger effects in HS + MES could be expected in metabolic syndrome or type 2 diabetes compared with those in healthy subjects. Changes in body compositions and biochemical markers on HS + MES treatment were summarized in Table 2 .

\section{Discussion}

NAFLD is a common complication of metabolic syndrome and type 2 diabetes mellitus. The spectrum of this disease is broad, ranging from simple steatosis, which is generally nonprogressive, through NASH to cirrhosis, liver failure, and even hepatocellular carcinoma.

In this study, we have observed that most of the NAFLD steatosis biomarkers in patients with metabolic syndrome and the NAFLD steatosis and fibrosis biomarkers in patients with type 2 diabetes were improved upon HS + MES treatment.

Excess amounts of lipids/fuels trigger low-grade inflammation in both adipocytes and the liver. This results in the development of NAFLD, which in turn contributes to impaired insulin signaling that involves the activation of c-Jun NH2-terminal kinases (JNK), nuclear factor (NF)-кB, 
$\Delta \mathrm{FLI}$

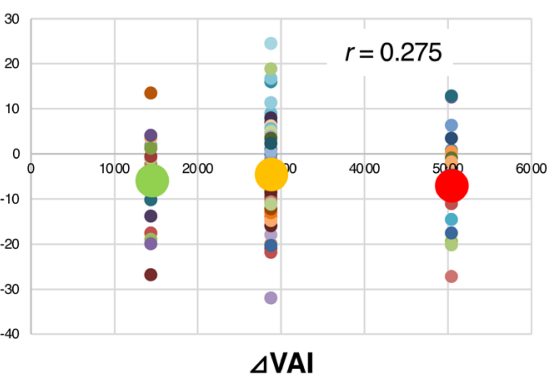

$\triangle \mathrm{VAl}$

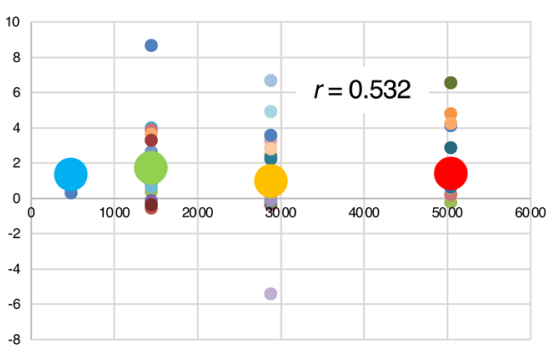

$\triangle$ FIB4

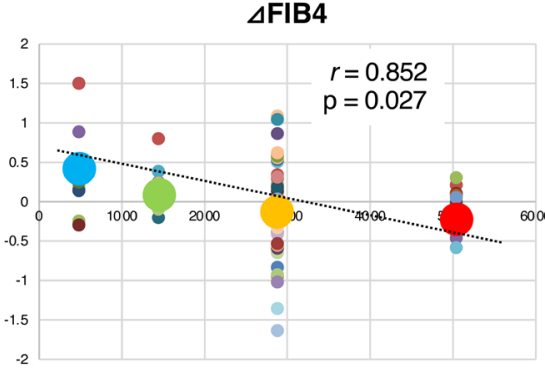

CET: 480 $\triangle$ NAFLD-LFS

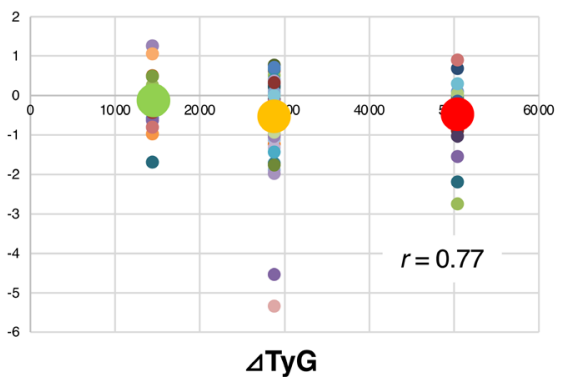

$\triangle \mathrm{TyG}$

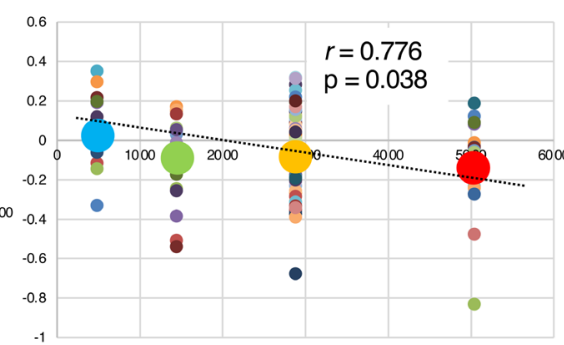

$\triangle \mathrm{NFS}$

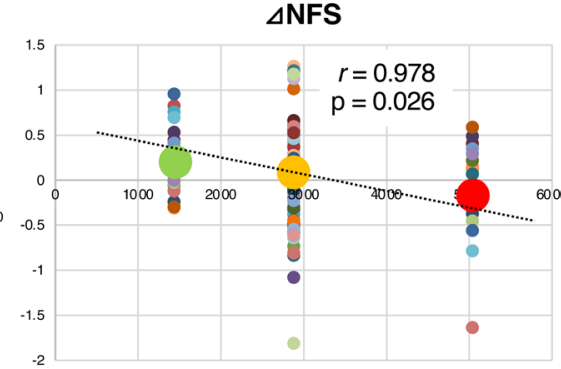

CET: 2880

CET: 1440

CET: 5040
$\Delta \mathrm{HSI}$

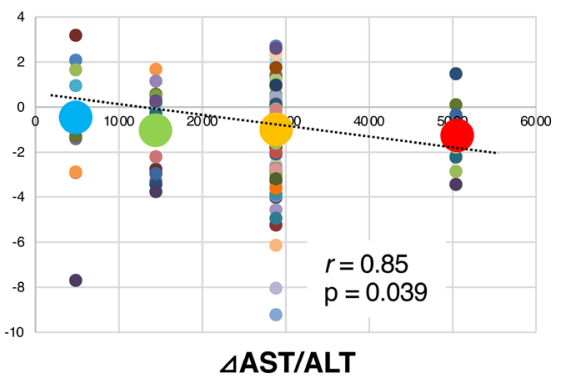

$\triangle \mathrm{AST} / \mathrm{ALT}$

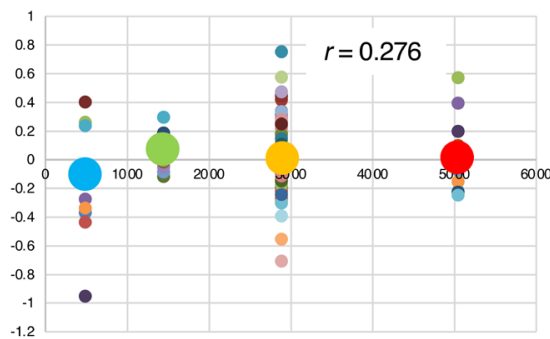

$\triangle \mathrm{APRI}$

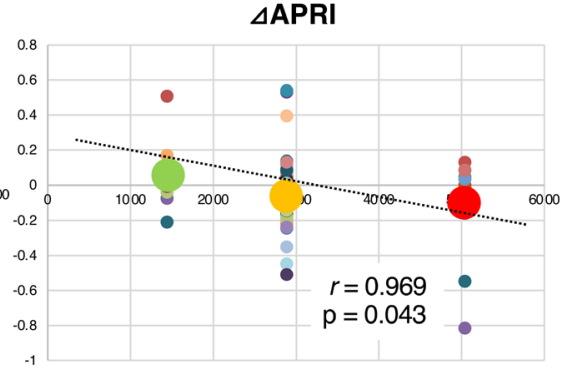

\section{Figure 3}

The univariable linear regression analysis on HS + MES treatment as cumulative exposure time. The changes of NAFLD biomarkers and HS + MES cumulative exposure time (CET: time $\times$ frequency/w $\times$ weeks) were plotted. The correlation coefficient $r$ and $P$ values were estimated. Blue dot: healthy subject (CET: 480). Light green dot: metabolic syndrome (CET: 2880). Dark green dot: type 2 diabetes (CET: 1440). Orange dot: type 2 diabetes (CET: 2880). Red dot: type 2 diabetes (CET: 5040).

transforming growth factor (TGF)- $\beta$, and ER stress in both humans and rodents (29).

A steatotic liver is susceptible to stressful loads such as ischemia-reperfusion injury during surgical intervention. Heat shock preconditioning provides steatotic rat livers with significant tolerance to ischemia-reperfusion injury (30). This may reflect improvements in hepatic microcirculation and reduction of free radicals by heat shock-induced HSP72 (30). Matrine, a medication used clinically for viral hepatitis and hepatic carcinoma, ameliorated visceral adiposity and glucose intolerance as effectively as metformin in high-fat-fed mice, with additional effects of reducing hepatic steatosis mainly due to HSP72 induction (31). Matrine also reportedly protects the liver from $\mathrm{CCl}_{4}$-induced fibrosis in rats (32). While reduced HSP72 expression in the skeletal muscle is correlated with insulin resistance (33), a similar correlation between reduced hepatic HSP72 expression and hepatosteatosis/glucose intolerance has been observed, suggesting that reduction of HSP72 might be a key mediator of metabolic disturbances in the liver (31). Other potential anti-diabetic compounds such as resveratrol (34), BGP-15 (35), naringin (36), $\alpha$-linolenic acid (37), and GGA (6) were shown to induce HSP72 expression in vitro and in vivo. In particular, GGA almost exclusively induces HSP72 in the liver of high-fat-fed mice and ameliorates glucose homeostasis as well as hepatic lipid accumulation (6). Thus, HSP72 induction by HS+MES is considered to be a major contributor to improve metabolic profiles and NAFLD biomarkers in metabolic syndrome and type 2 diabetes. Although we have not examined the expression of HSP72 in the liver of those participants, HSP72 induction on HS + MES treatment was observed in monocytes of the patients with metabolic syndrome (8).

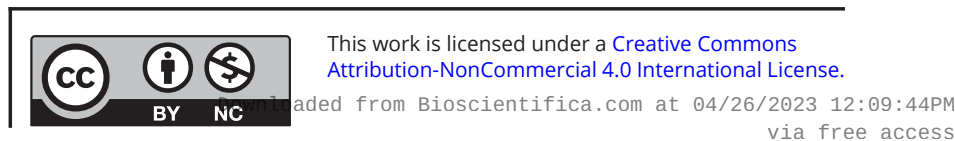




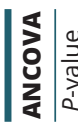
$\bar{\pi} \overline{0}$

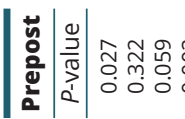

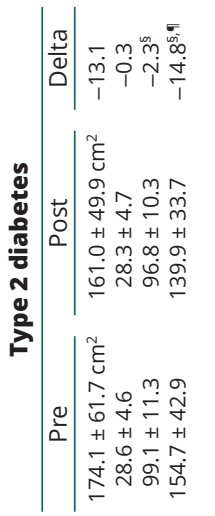

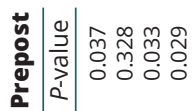

The intensity of the intervention in HS + MES estimated by cumulative exposure time (Fig. 3) may explain the effects of HS+MES for NAFLD biomarkers, indicating that the magnitude of the HSP72 induction may mediate these metabolic benefits. Archer et al. (38) reported that weekly in vivo hyperthermia improved glucose tolerance, elevated muscle and hepatic HSP72 protein content and reduced muscle triglyceride storage, suggesting that hyperthermia may improve systemic metabolism via the induction of hepatic HSP72. Additionally, an acute loss of HSP72 in primary hepatocytes impacts mitochondrial health as well as fat oxidation and storage. These findings suggest therapies targeting HSP72 in the liver may prevent NAFLD.

HSP72 transcriptional activation is positively regulated by heat shock transcription factor-1 (HSF1). Obesity triggers the differential regulation of various HSRs and decreases the HSF1 level in the liver, which correlates with the impairment of HSP72 in NAFLD (39). The HSF1HSP72 axis is progressively suppressed in the adipose tissue and liver of patients with obesity as NAFLD evolves (40). A clear negative correlation between the progression of NAFLD to fibrosis and the expression/activation of the HSF1/HSP72 biochemical pathway is observed in both the liver and adipose tissues of patients with NAFLD (40). This suppression of the HSF1-HSP72 axis is strongly correlated with the degree of enhancement of JNK activation (40), which contributes to the further enhancement of chronic inflammation and insulin resistance.

Conversely, HSP72 strongly inhibits JNK by several mechanisms (41) and protects cells from ER stress through the activation of the inositol-requiring enzyme 1-X-boxbinding protein-1 pathway (42). In addition, modulations of the HSP pathway have been shown to suppress canonical TGF- $\beta$ and NF-kB signaling. HSP72 blocks NF- $\mathrm{kB}$ activation at multiple aspects, such as by impeding inhibitor of $\kappa B$ (ІкB) phosphorylation (43) and by directly binding to ІкB kinase $\gamma$ (44). All of these target molecules of HSP72 are involved in the development and progression of NAFLD. Therefore, these anti-inflammatory and anti-fibrosis functions of HSP72 may contribute to the amelioration of NAFLD steatosis as well as fibrosis biomarkers. The other HSR-associated gene Sirtuin 1, an $\mathrm{NAD}^{+}$dependent class III histone deacetylase is also involved in the prevention of insulin resistance, and in the deacetylation of HSF1 to promote HSP transcription (45), and may have possible interactions to elicit the HS+MES effects on NAFLD biomarkers. Sirtuin 1 expression and HSF1 deacetylation should be examined upon HS + MES treatment if there are other pathways associated with HS+MES effects. 
Our investigation possesses several limitations. No liver biopsies or FibroScan examinations were performed to evaluate the exact NAFLD stages, and this study was not designed for prospective procedures. Additionally, no measurements of fragment of propeptide of type III collagen or cytokeratin-18 were performed. From the molecular point of view, we haven't assessed other heat shock proteins, such as HSP27, HSP40, HSP60 or HSP90. Although in vitro experiments using HS+MES identified HSP40 or HSP90 were not elevated in our model (46), the expression of other HSPs should be examined in vivo. Recent research identified that plasma lipid signatures may predict pathological lipid abundance in the liver of mice and humans (47). Although we have used several NAFLD biomarkers calculated by some biochemical or body composition parameters, plasma lipid signatures may predict and evaluate NAFLD more precisely. This strategy may identify promising diagnostic and prognostic NAFLD biomarkers. Although cumulative exposure time may explain the effects of HS+MES for NAFLD biomarkers, the differences in intervention dose and different cohorts limit our conclusions. We also have large variability in the study group, especially in age. In addition, as we have recruited only $12 \%$ of females in this study, this relatively largely imbalanced population in age and sex should be modified. Because above reasons and the relatively small numbers in subjects, we are now planning to prospectively evaluate the effects of a renewed, smaller, and easy-to-use HS + MES device on metabolic disturbances and NAFLD biomarkers in patients with type 2 diabetes.

\section{Conclusion}

In this study, most of the NAFLD steatosis biomarkers in patients with metabolic syndrome and the NAFLD steatosis and fibrosis biomarkers in patients with type 2 diabetes were improved upon HS+MES treatment. Because no NAFLD treatment strategy has been established so far, this is the first clinical manuscript to show that a medical device (physical medicine) may have a wide variety of clinical indications, including NAFLD, metabolic syndrome and type 2 diabetes. Thus, HS+MES, a physical intervention targeting HSP72, may become a novel treatment strategy for NAFLD as well as metabolic disorders, including metabolic syndrome and type 2 diabetes.

\section{Supplementary materials}

This is linked to the online version of the paper at https://doi.org/10.1530/ EC-21-0084

\section{Declaration of interest}

Eiichi Araki reports research funding (to his department) from Astellas Pharma, AstraZeneca, MSD, Ono Pharmaceutical, Kyowa Hakko Kirin, Sanofi, Shionogi, Takeda, Daiichi Sankyo, Mitsubishi Tanabe, Novo Nordisk, and Pfizer. Eiichi Araki reports lecture fees from Astellas Pharma, AstraZeneca, MSD, Ono Pharmaceutical, Kowa Pharmaceutical, Sanofi, Takeda, Mitsubishi Tanabe, Eli Lilly, Novo Nordisk, and Taisho Pharma. The other authors report no potential conflicts of interest relevant to this article.

\section{Funding}

This study was supported by the Japanese Government (MEdical Device InCubation (MEDIC) platform from the Ministry of Economy, Trade and Industry Japan; Grant No. 24-065). The sponsor of this study had no role in the study design, data collection, data analysis, data interpretation, or writing of the report

\section{Patient consent}

Informed consent was obtained from all subjects.

\section{Author contribution statement}

Tatsuya Kondo has full access to all data in the study and takes responsibility for the integrity of the data and the accuracy of the data analysis. Study concept or design was done by Tatsuya Kondo, Nobukazu Miyakawa, Hirofumi Kai, Eiichi Araki. Acquisition of data was done by Tatsuya Kondo, Nobukazu Miyakawa, Sayaka Kitano, Takuro Watanabe, Rieko Goto, Mary Ann Suico, Miki Sato, Yuki Takaki, Masaji Sakaguchi, Motoyuki Igata, Junji Kawashima, Hiroyuki Motoshima, Takeshi Matsumura, Eiichi Araki. Tatsuya Kondo and Nobukazu Miyakawa analyzed and interpreted the data. All authors were involved in the drafting and critical revision of the manuscript for important intellectual content. Statistical analysis was performed by Tatsuya Kondo and Nobukazu Miyakawa. Funds were obtained by Tatsuya Kondo and Eiichi Araki. Hirofumi Kai and Eiichi Araki supervised the study.

\section{Acknowledgments}

The device used for HS + MES treatment was kindly provided by the Tsuchiya Rubber Co., Ltd. (Kumamoto, Japan). The authors thank Angela Morben, DVM, ELS, from Edanz Group (https://en-author-services. edanzgroup.com/), for editing a draft of this manuscript.

\section{References}

1 Anstee QM, Reeves HL, Kotsiliti E, Govaere O \& Heikenwalder M. From NASH to HCC: current concepts and future challenges. Nature Reviews: Gastroenterology and Hepatology 201916 411-428. (https:// doi.org/10.1038/s41575-019-0145-7)

2 Bedi O, Aggarwal S, Trehanpati N, Ramakrishna G \& Krishan P. Molecular and pathological events involved in the pathogenesis of diabetes-associated nonalcoholic fatty liver disease. Journal of Clinical and Experimental Hepatology 20199 607-618. (https://doi. org/10.1016/j.jceh.2018.10.004)

3 Kadowaki S, Tamura Y, Someya Y, Takeno K, Kaga H, Sugimoto D, Kakehi S, Funayama T, Furukawa Y, Suzuki R, et al. Fatty liver has stronger association with insulin resistance than visceral fat accumulation in nonobese Japanese men. Journal of the Endocrine Society 20193 1409-1416. (https://doi.org/10.1210/js.2019-00052) 4 Rohrl C, Eigner K, Winter K, Korbelius M, Obrowsky S, Kratky D, Kovacs WJ \& Stangl H. Endoplasmic reticulum stress impairs

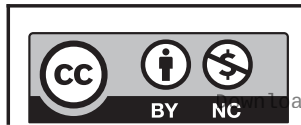

This work is licensed under a Creative Commons Attribution-NonCommercial 4.0 International License. ded from Bioscientifica.com at 04/26/2023 12:09:44PM 
cholesterol efflux and synthesis in hepatic cells. Journal of Lipid Research 201455 94-103. (https://doi.org/10.1194/jlr.M043299)

5 Zhou H \& Liu R. ER stress and hepatic lipid metabolism. Frontiers in Genetics 20145 112. (https://doi.org/10.3389/fgene.2014.00112)

6 Adachi H, Kondo T, Ogawa R, Sasaki K, Morino-Koga S, Sakakida M, Kawashima J, Motoshima H, Furukawa N, Tsuruzoe K, et al. An acylic polyisoprenoid derivative, geranylgeranylacetone protects against visceral adiposity and insulin resistance in high fat fed mice. American Journal of Physiology: Endocrinology and Metabolism 2010299 E764-E771. (https://doi.org/10.1152/ ajpendo.00075.2010)

7 Kondo T, Goto R, Ono K, Kitano S, Suico MA, Sato M, Igata M, Kawashima J, Motoshima H, Matsumura T, et al. Activation of heat shock response to treat obese subjects with type 2 diabetes: a prospective, frequency-escalating, randomized, open-label, triplearm trial. Scientific Reports 20166 35690. (https://doi.org/10.1038/ srep35690)

8 Kondo T, Ono K, Kitano S, Matsuyama R, Goto R, Suico MA, Kawasaki S, Igata M, Kawashima J, Motoshima H, et al. Mild electrical stimulation with heat shock reduces visceral adiposity and improves metabolic abnormalities in subjects with metabolic syndrome or type 2 diabetes: randomized crossover trials. EBiomedicine 20141 80-89. (https://doi.org/10.1016/j.ebiom.2014.11.001)

9 Kitano S, Kondo T, Matsuyama R, Ono K, Goto R, Takaki Y, Hanatani S, Sakaguchi M, Igata M, Kawashima J, et al. Impact of hepatic HSP72 on insulin signaling. American Journal of Physiology: Endocrinology and Metabolism 2019316 E305-E318. (https://doi. org/10.1152/ajpendo.00215.2018)

10 Kondo T, Sasaki K, Adachi H, Nakayama Y, Hatemura M, Matsuyama R, Tsuruzoe K, Furukawa N, Motoshima H, Morino S, et al. Heat shock treatment with mild electrical stimulation safely reduced inflammatory markers in healthy male subjects. Obesity Research and Clinical Practice 20104 e83-e162. (https://doi. org/10.1016/j.orcp.2009.09.007)

11 Haneda M, Noda M, Origasa H, Noto H, Yabe D, Fujita Y, Goto A, Kondo T \& Araki E. Japanese clinical practice guideline for diabetes 2016. Journal of Diabetes Investigation 20183 657-697. (https://doi. org/10.1111/jdi.12810)

12 Matsuzawa Y. Metabolic syndrome - definition and diagnostic criteria in Japan. Journal of Atherosclerosis and Thrombosis 200512 301. (https://doi.org/10.5551/jat.12.301)

13 American Diabetes Association. Standards of medical care in diabetes - 2013. Diabetes Care 201336 (Supplement 1) S11-S66. (https://doi. org/10.2337/dc13-S011)

14 Bedogni G, Bellentani S, Miglioli L, Masutti F, Passalacqua M, Castiglione A \& Tiribelli C. The fatty liver index: a simple and accurate predictor of hepatic steatosis in the general population. BMC Gastroenterology 20066 33. (https://doi.org/10.1186/1471230X-6-33)

15 Fedchuk L, Nascimbeni F, Pais R, Charlotte F, Housset C, Ratziu V \& LIDO Study Group. Performance and limitations of steatosis biomarkers in patients with nonalcoholic fatty liver disease. Alimentary Pharmacology and Therapeutics 201440 1209-1222. (https://doi.org/10.1111/apt.12963)

16 Kotronen A, Peltonen M, Hakkarainen A, Sevastianova K, Bergholm R, Johansson LM, Lundbom N, Rissanen A, Ridderstrale M, Groop L, et al. Prediction of non-alcoholic fatty liver disease and liver fat using metabolic and genetic factors. Gastroenterology $2009 \mathbf{1 3 7}$ 865-872. (https://doi.org/10.1053/j.gastro.2009.06.005)

17 Yoneda M, Iwasaki T, Fujita K, Kirikoshi H, Inamori M, Nozaki Y, Maeyama S, Wada K, Saito S, Terauchi Y, et al. Hypoadiponectinemia plays a crucial role in the development of nonalcoholic fatty liver disease in patients with type 2 diabetes mellitus independent of visceral adipose tissue. Alcoholism, Clinical and Experimental Research 200731 (Supplement) S15-S21. (https://doi.org/10.1111/j.15300277.2006.00281.x)
18 Ohki T, Tateishi R, Shiina S, Goto E, Sato T, Nakagawa H, Masuzaki R, Goto T, Hamamura K, Kanai F, et al. Visceral fat accumulation is an independent risk factor for hepatocellular carcinoma recurrence after curative treatment in patients with suspected NASH. Gut 200958 839-844. (https://doi.org/10.1136/ gut.2008.164053)

19 Lee JH, Kim D, Kim HJ, Lee CH, Yang JI, Kim W, Kim YJ, Yoon JH, Cho SH, Sung MW, et al. Hepatic steatosis index: a simple screening tool reflecting nonalcoholic fatty liver disease. Digestive and Liver Disease 201042 503-508. (https://doi.org/10.1016/j. dld.2009.08.002)

20 Petta S, Amato M, Cabibi D, Camma C, Di Marco V, Giordano C, Galluzzo A \& Craxi A. Visceral adiposity index is associated with histological findings and high viral load in patients with chronic hepatitis C due to genotype 1. Hepatology 201052 1543-1552. (https://doi.org/10.1002/hep.23859)

21 Guerrero-Romero F, Simental-Mendia LE, Gonzalez-Ortiz M, Martinez-Abundis E, Ramos-Zavala MG, Hernandez-Gonzalez SO, Jacques-Camarena $\mathrm{O} \&$ Rodriguez-Moran $\mathrm{M}$. The product of triglycerides and glucose, a simple measure of insulin sensitivity. Comparison with the euglycemic-hyperinsulinemic clamp. Journal of Clinical Endocrinology and Metabolism 201095 3347-3351. (https:// doi.org/10.1210/jc.2010-0288)

22 De Ritis F, Coltorti M \& Giusti G. An enzymic test for the diagnosis of viral hepatitis; the transaminase serum activities. Clinica Chimica Acta 19572 70-74. (https://doi.org/10.1016/0009-8981(57)90027-X)

23 Wong VW, Adams LA, de Ledinghen V, Wong GL \& Sookoian S. Noninvasive biomarkers in NAFLD and NASH - current progress and future promise. Nature Reviews: Gastroenterology and Hepatology 2018 15 461-478. (https://doi.org/10.1038/s41575-018-0014-9)

24 Botros M \& Sikaris KA. The de ritis ratio: the test of time. Clinical Biochemist Reviwes 201334 117-130.

25 Sterling RK, Lissen E, Clumeck N, Sola R, Correa MC, Montaner J, S Sulkowski M, Torriani FJ, Dieterich DT, Thomas DL, et al. Development of a simple noninvasive index to predict significant fibrosis in patients with HIV/HCV coinfection. Hepatology 200643 1317-1325. (https://doi.org/10.1002/hep.21178)

26 Sumida Y, Yoneda M, Hyogo H, Itoh Y, Ono M, Fujii H, Eguchi Y, Suzuki Y, Aoki N, Kanemasa K, et al. Validation of the FIB4 index in a Japanese nonalcoholic fatty liver disease population. BMC Gastroenterology 201212 2. (https://doi.org/10.1186/1471-230X-12-2)

27 Angulo P, Hui JM, Marchesini G, Bugianesi E, George J, Farrell GC, Enders F, Saksena S, Burt AD, Bida JP, et al. The NAFLD fibrosis score: a noninvasive system that identifies liver fibrosis in patients with NAFLD. Hepatology 200745 846-854. (https://doi.org/10.1002/ hep.21496)

28 Borroni G, Ceriani R, Cazzaniga M, Tommasini M, Roncalli M, Maltempo C, Felline C \& Salerno F. Comparison of simple tests for the non-invasive diagnosis of clinically silent cirrhosis in chronic hepatitis C. Alimentary Pharmacology and Therapeutics 200624 797-804. (https://doi.org/10.1111/j.1365-2036.2006.03034.x)

29 Hotamisligil GS. Role of endoplasmic reticulum stress and c-Jun NH2-terminal kinase pathways in inflammation and origin of obesity and diabetes. Diabetes 200554 (Supplement 2) S73-S78. (https://doi. org/10.2337/diabetes.54.suppl_2.s73)

30 Yamagami K, Yamamoto Y, Kume M, Kimoto S, Yamamoto H, Ozaki N, Yamamoto M, Shimahara Y, Toyokuni S \& Yamaoka Y. Heat shock preconditioning ameliorates liver injury following normothermic ischemia-reperfusion in steatotic rat livers. Journal of Surgical Research 199879 47-53. (https://doi.org/10.1006/ jsre.1998.5403)

31 Zeng XY, Wang H, Bai F, Zhou X, Li SP, Ren LP, Sun RQ, Xue CC, Jiang HL, Hu LH, et al. Identification of matrine as a promising novel drug for hepatic steatosis and glucose intolerance with HSP72 as an upstream target. British Journal of Pharmacology $20151724303-4318$. (https://doi.org/10.1111/bph.13209)

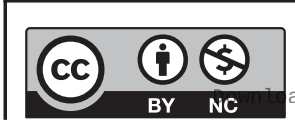


32 Zhang JP, Zhang M, Zhou JP, Liu FT, Zhou B, Xie WF \& Guo C. Antifibrotic effects of matrine on in vitro and in vivo models of liver fibrosis in rats. Acta Pharmacologica Sinica 200122 183-186.

33 Kurucz I, Morva A, Vaag A, Eriksson KF, Huang X, Groop L \& Koranyi L. Decreased expression of heat shock protein 72 in skeletal muscle of patients with type 2 diabetes correlates with insulin resistance. Diabetes 200251 1102-1109. (https://doi.org/10.2337/ diabetes.51.4.1102)

34 Putics A, Vegh EM, Csermely P \& Soti C. Resveratrol induces the heat-shock response and protects human cells from severe heat stress. Antioxidants and Redox Signaling 200810 65-75. (https://doi. org/10.1089/ars.2007.1866)

35 Chung J, Nguyen AK, Henstridge DC, Holmes AG, Chan MH, Mesa JL, Lancaster GI, Southgate RJ, Bruce CR, Duffy SJ, et al. HSP72 protects against obesity-induced insulin resistance. PNAS $2008 \mathbf{1 0 5}$ 1739-1744. (https://doi.org/10.1073/pnas.0705799105)

36 Sharma AK, Bharti S, Ojha S, Bhatia J, Kumar N, Ray R, Kumari S \& Arya DS. Up-regulation of PPARgamma, heat shock protein-27 and -72 by naringin attenuates insulin resistance, beta-cell dysfunction, hepatic steatosis and kidney damage in a rat model of type 2 diabetes. British Journal of Nutrition 2011106 1713-1723. (https:// doi.org/10.1017/S000711451100225X)

37 Goncalves NB, Bannitz RF, Silva BR, Becari DD, Poloni C, Gomes PM, Foss MC \& Foss-Freitas MC. Alpha-linolenic acid prevents hepatic steatosis and improves glucose tolerance in mice fed a high-fat diet. Clinics 201873 e150. (https://doi.org/10.6061/clinics/2018/e150)

38 Archer AE, Rogers RS, Von Schulze AT, Wheatley JL, Morris EM, McCoin CS, Thyfault JP \& Geiger PC. Heat shock protein 72 regulates hepatic lipid accumulation. American Journal of Physiology: Regulatory, Integrative and Comparative Physiology 2018315 R696-R707. (https:// doi.org/10.1152/ajpregu.00073.2018)

39 Tiss A, Khadir A, Abubaker J, Abu-Farha M, Al-Khairi I, Cherian P, John J, Kavalakatt S, Warsame S, Al-Ghimlas F, et al. Immunohistochemical profiling of the heat shock response in obese non-diabetic subjects revealed impaired expression of heat shock proteins in the adipose tissue. Lipids in Health and Disease 201413 106. (https://doi.org/10.1186/1476-511X-13-106)
40 Di Naso FC, Porto RR, Fillmann HS, Maggioni L, Padoin AV, Ramos RJ, Mottin CC, Bittencourt A, Marroni NA \& de Bittencourt Jr PI. Obesity depresses the anti-inflammatory HSP70 pathway, contributing to NAFLD progression. Obesity 201523 120-129. (https://doi.org/10.1002/oby.20919)

41 Morino S, Kondo T, Sasaki K, Adachi H, Suico MA, Sekimoto E, Matsuda T, Shuto T, Araki E \& Kai H. Mild electrical stimulation with heat shock ameliorates insulin resistance via enhanced insulin signaling. PLoS ONE 20083 e4068. (https://doi.org/10.1371/journal. pone.0004068)

42 Gupta S, Deepti A, Deegan S, Lisbona F, Hetz C \& Samali A. HSP72 protects cells from ER stress-induced apoptosis via enhancement of IRE1alpha-XBP1 signaling through a physical interaction. PLoS Biology 20108 e1000410. (https://doi.org/10.1371/journal. pbio.1000410)

43 Chan JY, Ou CC, Wang LL \& Chan SH. Heat shock protein 70 confers cardiovascular protection during endotoxemia via inhibition of nuclear factor-kappaB activation and inducible nitric oxide synthase expression in the rostral ventrolateral medulla. Circulation 2004110 3560-3566. (https://doi.org/10.1161/01. CIR.0000143082.63063.33)

44 Chen HW, Kuo HT, Wang SJ, Lu TS \& Yang RC. In vivo heat shock protein assembles with septic liver NF-kappaB/I-kappaB complex regulating NF-kappaB activity. Shock 200524 232-238. (https://doi. org/10.1097/01.shk.0000174020.87439.f2)

45 Martins IJ. Heat shock gene inactivation and protein aggregation with links to chronic diseases. Diseases 20186 39. (https://doi. org/10.3390/diseases6020039)

46 Morino S, Suico MA, Kondo T, Sekimoto E, Yano S, Matsuda T, Matsuno T, Shuto T, Araki E \& Kai H. Mild electrical stimulation increases ubiquitinated proteins and Hsp72 in A549 cells via attenuation of proteasomal degradation. Journal of Pharmacological Sciences 2008108 222-226. (https://doi.org/10.1254/jphs.08180SC)

47 Parker BL, Calkin AC, Seldin MM, Keating MF, Tarling EJ, Yang P, Moody SC, Liu Y, Zerenturk EJ, Needham EJ, et al. An integrative systems genetic analysis of mammalian lipid metabolism. Nature 2019567 187-193. (https://doi.org/10.1038/s41586-019-0984-y)

Received in final form 14 April 2021

Accepted 21 April 2021

Accepted Manuscript published online 22 April 2021
This work is licensed under a Creative Commons Attribution-NonCommercial 4.0 International License. ded from Bioscientifica.com at 04/26/2023 12:09:44PM 